\title{
Selection of Parameters of Current Collection Systems of Turbo-Generators to be Monitored by Means of Technical Diagnostics
}

\author{
Alexander Markov, Pskov State University, Yuri Rodionov, Ecotech Ltd, Pskov
}

\begin{abstract}
In this article the choice of parameters of the current collection systems is substantiates, which must be monitored by technical means. It is shown that such parameters are the intensity of the sparking under brushes, uniformity of current distribution on parallel brushes, vibrations and runout slip rings and the state of their surface.

For monitoring these parameters Ecotech Ltd (Pskov) develops a hardware-software complex.

Complex consists of the following devices: - device to monitor the intensity of sparking, - device for measuring the current of brushes, - device for measuring vibrations and runout, - device for exploring the surface of rotating slip rings.
\end{abstract}

Development of hardware-software complex is supported by the Foundation for Assistance to Small Innovative Enterprises in the scientific and technical field.

Keywords - turbo-generator, current collection system, current distribution, sparking, vibrations, hardwaresoftware complex.

\section{INTRODUCTION}

It is known that current collection system of turbogenerator is the least reliable. For example according to the Department of general inspection of operation (Russia) current collection system takes the first place by accident, on its share is more than $25 \%$ of all accidents turbo-generators.

The reason of the unsatisfactory situation with the reliability of the current collection system is that monitoring tools in power plants are absent.

This article is devoted to justifying the choice of the parameters of current collection systems, which are subject to mandatory monitoring by the hardwaresoftware complex for a permanent monitoring of current collection systems. Also a block scheme of hardware-software complex and technical specifications of devices are presented.

And finally the article contains the results of testing the devices.

Now the operation of current collection systems of turbo-generators is carried out in accordance with the operating instructions of JSC «Electrosila» and the firm ORGRES. The instruction of the JSC «Electrosila» [1] provides for monitoring of 12 specific problems. The ORGRES instruction [2] contains a list of 64 causes of violations in the operation of the current collection systems, it also shows the 38 signs of violations in the operation.

Obviously such a long list of monitored parameters using a hardware-software complex is not possible and it is not necessary for several reasons.

First, a significant part of the settings more easily and efficiently controlled visually. For example brush damages, the presence of discoloration on pressure springs, mechanical damages of various elements of the current collection system and others damages are easy to control by visually.
Second, many irregularities in the current collection system appear in the same way. For example in the form of sparking may occur deterioration turbine vibration condition, incorrect pressure on the brush, the deterioration of the profile or contaminated surfaces of slip rings, uneven current distribution on the brushes, the lack of humidity in the engine room, poor quality brushes, uneven brush wear.

Third, the number of parameters does not make sense to control by hardware-software complex, as they are caused by natural factors of production of power stations such as turbine start, the critical frequency at turbine start, works for rotor balancing, no isolation between the brush holder and the traverse.

Thus, from the above it follows that monitoring through the hardware-software complex to be fairly limited set of parameters.

The rationale for its selection is as follows.

\section{JUSTIFICATION OF THE NECESSITY TO MONITOR THE INTENSITY OF SPARKING}

The instruction of the JSC «Electrosila» requires regularly (at least once a day) to inspect the current collection system and visually evaluate its work in sparking, as the sparks of carbon brushes is the indicator of the current collection system, and it is necessary to monitor its intensity.

According to this instruction should distinguish three types of brush sparking:

1. Sparking a large number of brushes, having the form of sparks flying away, the path which ends with an asterisk. This type of sparking is the combustion of small ferroparticles in oxygen air. Sparking cause is the lack of contact pressure of brushes or its high vibration.

To reduce or eliminate sparking you should increase the contact pressure at all brushes of 
sparkling slip rings. If this measure does not give the desired effect then you need to check or improve the shape of the contact surface of the slip rings by machining or balancing to reduce the vibrations. In urgent cases you can resort to manual polishing of slip rings surface without turning off the turbo-generator.

2. Sparking a small number of brushes, accompanied by the destruction of the brush material. This type of sparking due to sharp violation of the current distribution between the parallel brushes. It should reduce the contact pressure of the overloaded brushes.

Sparking between the side surfaces of brushes and the inner walls of brush holders. The reason for this sparking is the violation of contact between the brush and conductor. Defective brushes should be replaced by new ones, preferably of one plant with similar physical and mechanical properties. The contact pressure of new brushes should be at $30-40 \%$ less than the old, fully lapped. In all cases the intermediate pressure on the brush should be set in proportion to its degree of grinding.

Daily visual control of operation of the current collection system aims to determine timely the beginning of the sparking gain. Purpose - manual grinding of contact rings, a temporary reduction in the current load of the rotor or otherwise.

When the circular fire appears turbo-generator must be immediately disconnected from the network.

The instruction of JSC «Electrosila» allows $1 \frac{1}{4}$ sparking of brushes according to «Rotating electrical machines. General specifications».

Instruction ORGRES [2] contains similar requirements for monitoring sparking and also notes the importance of monitoring of this parameter. For example paragraph 3.1 .1 of this instruction indicates that the turbine must be disabled in emergency, removed the excitement and the turbo-generator is disconnected from the network when a circular fire at one or both poles appears and in intensive sparking.

Instruction ORGRES admits sparking of degrees 1 and $1 \frac{1}{4}$. When sparking degree is more than $1 \frac{1 / 4}{4}$ it is necessary to take special precautions to reduce it. Namely you must relieve the turbo-generator reactive power and produce extraordinary vibration measurement of slip rings. If the allowable vibration values (300 microns) is exceed you should take steps to eliminate it.

Thus the intensity of sparking is a subject of mandatory monitoring. However the instructions require to control it visually and very rarely (once a day). This makes it impossible to detect timely the sparking began. The consequence of this is the development of sparking up the circular fire with a turbo-generator emergency stop.

Consequently there is a need to monitor the intensity of sparking under brushes constantly using the hardware-software complex.

\section{JUSTIFICATION OF THE NECESSITY TO MONITOR THE UNIFORMITY OF THE CURRENT DISTRIBUTION}

Instructions JSC "Electrosila" indicates that the monitoring of current collection system and its adjustment are to ensure similar meaning of currents of parallel brushes. However, the instructions do not have any indications of the instruments with which to measure the current of brushes.

Current of brush is proposed to determine indirectly, by temperature of brush wire. Brush with more hot conductors require relieving the pressure, with more cold - increasing. Conductor temperature should be determined by hand. Obviously that this method cannot measure the current brushes.

The instructions ORGRES also indicates that the adjustment of current collection system is to provide as uniform loading of each brush. Current measurement should be made with the help of indicators DC. In other words, devices specifically designed for the measurement of currents brush does not exist.

As a result the number of failures of turbogenerators is maintained at a high level. The situation is aggravated by the fact that there is a decrease in the qualification of the staff, falling technical education.

Thus monitoring of uniformity of the current distribution between brushes with the use of hardware-software complex is necessary.

\section{JUSTIFICATION OF THE NECESSITY TO MONITOR VIBRATIONS OF SLIP RINGS}

Vibrations and runout of slip rings are an important parameter of the current collection system. It characterizes the quality of the surface of slip rings. According to the instructions of JSC "Electrpsila" vibrations and runout are measured by a special indicator. The value of vibration should not exceed 300 microns, runout -50 microns

Vibrations measurements should be made once a month at least. Measurements are carry out under steady-state mode of turbo-generator and at the same rotor current. If the vibrations are more than 300 microns it is necessary to take steps to eliminate it.

The instruction allows the operation of turbogenerator with the vibrations of more than 300 microns. In this case there should be no unacceptable sparking, destruction of brushes, large heating. If it is impossible to ensure these conditions it is necessary to stop the turbo-generator. The negative consequences of high vibrations are high mechanical wear of slip rings and brushes.

\section{JUSTIFICATION OF THE NECESSITY TO MONITOR THE STATE OF THE SURFACE OF SLIP RINGS}

The instructions need to pay special attention to the surface state of the slip rings. It should not have defects. The surface state should be evaluated once a day visually. Obviously that you can evaluate the surface state visually only slip rings are fixed. 
Thus the state of the surface of contact rings determines the state and quality of current collection system.

Therefore, this parameter should be monitored. It should be monitored not visually but using a special device and when the rings are rotating with an angular speed of $3000 \mathrm{rev} / \mathrm{min}$.

\section{HARDWARE-SOFTWARE COMPLEX}

So there is a necessity to monitor sparking brushes, uniform current distribution, vibrations of slip rings, state of the surface of the rings.

Today the company Ecotech Ltd (Pskov, Russia) develops hardware-software complex for monitoring these four parameters. The complex consists the following devices [3]:

- device for monitoring the intensity of sparking under brushes,

- device for measuring current of brushes,

- device for measuring vibrations and runout,

- device for exploring the surface of the rotating slip rings. This device will be auxiliary.

The block scheme of the hardware-software complex is shown in Fig. 1.

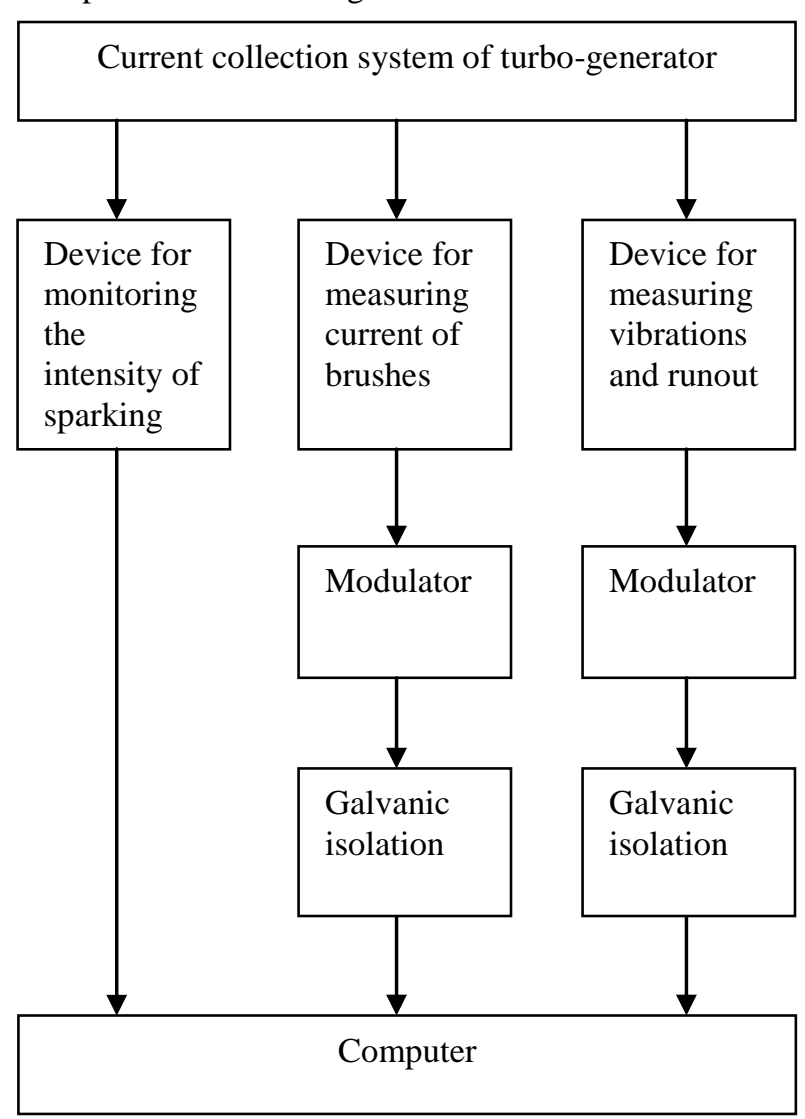

Fig. 1. Block scheme of hardware-software complex

Device for monitoring the intensity of sparking has two identical channels of measurement. This allows to use them to monitor sparking of both positive and negative polarities.

Information about the intensity of sparking appears in three forms:
- three-color alarm («red», «yellow», «green»), which characterizes the degree of sincerity;

- sound alarm, buzzer sounds in large sparking case. Buzzer locates where the staff is always present;

- analog form of alarm, on the front panel there is an indicator, the scale of which is divided into 4 zones:

a) lack of sparking or sparking level is equal 1 ;

b) poor sparking or sparking level is equal $1 \frac{1 / 4}{4}$ or $1 \frac{1}{2}$;

c) strong sparking or sparking level is equal 2;

d) invalid sparking (circular fire) or sparking level is equal 3 and more.

This device has two receiving antennas, one for each slip ring. Each antenna is placed in a protective screen and fixed under the cover of current collection system near its ring. Galvanic connection between the antennas and current collection system is absent.

Technical specifications of this device are:

$\begin{array}{ll}\text { voltage } & 220 \mathrm{~V}, 50 \mathrm{~Hz}, \\ \text { power } & 60 \mathrm{~W},\end{array}$

mode of operation continuous.

When adjusting the current collection system you should strive for setting up the same currents of all brushes. Practice of operation shows that current of one brush rarely exceeds $100 \mathrm{~A}$. Therefore when developing the device for measuring currents of brushes it was decided to establish the limits of measurement of brush from 0 A to $100 \mathrm{~A}$.

The device has a sensor of the «hook» to cover the funicle brushes. As each brush has two current carrying funicle, the measurements are performed separately for each of them.

Another device of the complex measures vibrations and runout of slip rings at all speeds of rotation. Resolution of this device is 0,5 microns. Ranges of the measured vibrations are 0-50, 0-100, 0-150, 0-200, 0-250, 0-300, 0-350, 0-400, 0-450, 0-500 microns.

\section{TESTING OF THE DEVICE FOR MEASURING CURRENT OF BRUSHES}

Testing of this device was performed on the experimental stand of Ecotech Ltd. It is based on the current collection system (Fig. 2).

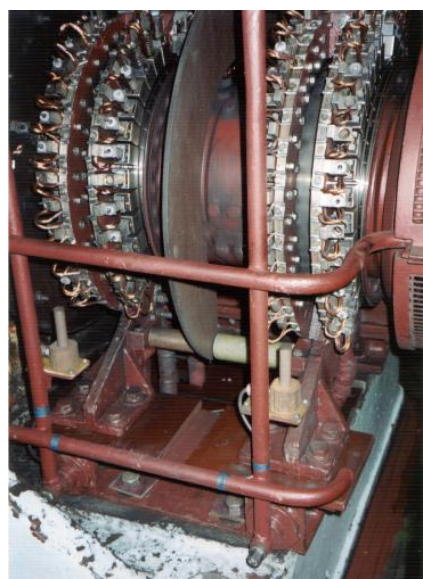

Fig. 2. Current collection system of experimental stand 
The results of measurements of currents of brushes are presented in Table I. The numerator gives the values of the currents measured by the device, the denominator gives the exact values of the currents. The exact value is obtained by using shunts. You can see that the exact value is very close coincides with the measured by the device.

TABLE I

THE RESULTS OF MEASUREMENTS OF CURRENT

\begin{tabular}{|c|c|c|c|c|c|c|c|c|c|c|}
\hline \multirow{3}{*}{$\begin{array}{l}\frac{\tilde{u}}{\tilde{u}} \\
\frac{\tilde{y}}{n}\end{array}$} & \multicolumn{5}{|c|}{$\begin{array}{l}\text { Negative ring } \\
\text { (brushes EG-2AF) }\end{array}$} & \multicolumn{5}{|c|}{$\begin{array}{l}\text { Positive ring } \\
\text { (brushes } 611 \mathrm{OM} \text { ) }\end{array}$} \\
\hline & \multicolumn{5}{|c|}{ Number of brush } & \multicolumn{5}{|c|}{ Number of brush } \\
\hline & 1 & 2 & 3 & 4 & 5 & 1 & 2 & 3 & 4 & 5 \\
\hline \multirow{2}{*}{1} & $\underline{30}$ & $\underline{37}$ & $\underline{28}$ & $\underline{31}$ & $\underline{30}$ & $\underline{40}$ & $\underline{37}$ & $\underline{23}$ & $\underline{55}$ & $\underline{25}$ \\
\hline & 30 & 30 & 28 & 30 & 33 & 38 & 38 & 28 & 50 & 31 \\
\hline \multirow{2}{*}{2} & $\underline{25}$ & $\underline{25}$ & $\underline{43}$ & $\underline{16}$ & $\underline{61}$ & $\underline{30}$ & 27 & $\underline{42}$ & $\underline{40}$ & 65 \\
\hline & 28 & 28 & 35 & 20 & 73 & 26 & 34 & 37 & 33 & 72 \\
\hline \multirow{2}{*}{3} & $\underline{48}$ & $\underline{52}$ & $\underline{60}$ & $\underline{40}$ & $\underline{32}$ & $\underline{56}$ & $\underline{43}$ & $\underline{84}$ & $\underline{46}$ & $\underline{34}$ \\
\hline & 45 & 45 & 48 & 35 & 36 & 58 & 38 & 78 & 41 & 31 \\
\hline \multirow{2}{*}{4} & $\underline{24}$ & $\underline{33}$ & $\underline{54}$ & $\underline{56}$ & $\underline{85}$ & $\underline{80}$ & $\underline{50}$ & $\underline{63}$ & 47 & 77 \\
\hline & 30 & 35 & 41 & 50 & 91 & 97 & 42 & 58 & 46 & 72 \\
\hline \multirow{2}{*}{5} & $\underline{33}$ & $\underline{39}$ & $\underline{47}$ & $\underline{76}$ & $\underline{23}$ & $\underline{16}$ & $\underline{25}$ & $\underline{22}$ & $\underline{85}$ & $\underline{26}$ \\
\hline & 34 & 31 & 49 & 68 & 34 & 17 & 30 & 18 & 87 & 35 \\
\hline \multirow{2}{*}{6} & $\underline{74}$ & $\underline{38}$ & $\underline{70}$ & $\underline{25}$ & $\underline{14}$ & $\underline{28}$ & $\underline{36}$ & $\underline{31}$ & $\underline{41}$ & $\underline{33}$ \\
\hline & 68 & 35 & 68 & 30 & 20 & 30 & 32 & 30 & 38 & 27 \\
\hline \multirow{2}{*}{7} & $\underline{22}$ & $\underline{51}$ & $\underline{66}$ & $\underline{60}$ & $\underline{47}$ & $\underline{17}$ & $\underline{27}$ & $\underline{74}$ & $\underline{17}$ & $\underline{30}$ \\
\hline & 27 & 46 & 61 & 55 & 40 & 20 & 31 & 81 & 20 & 27 \\
\hline \multirow[b]{2}{*}{8} & $\underline{74}$ & $\underline{79}$ & $\underline{37}$ & $\underline{20}$ & $\underline{21}$ & $\underline{43}$ & $\underline{26}$ & $\underline{24}$ & $\underline{36}$ & $\underline{31}$ \\
\hline & 68 & 60 & 30 & 25 & 25 & 40 & 30 & 28 & 41 & 40 \\
\hline \multirow[b]{2}{*}{9} & $\underline{22}$ & $\underline{16}$ & $\underline{35}$ & $\underline{29}$ & $\underline{16}$ & $\underline{44}$ & $\underline{23}$ & $\underline{40}$ & $\underline{21}$ & $\underline{32}$ \\
\hline & 27 & 25 & 30 & 30 & 22 & 46 & 26 & 38 & 26 & 30 \\
\hline \multirow{2}{*}{10} & $\underline{74}$ & $\underline{24}$ & $\underline{18}$ & $\underline{30}$ & $\underline{44}$ & $\underline{68}$ & $\underline{19}$ & $\underline{23}$ & $\underline{35}$ & $\underline{14}$ \\
\hline & 68 & 30 & 21 & 35 & 40 & 80 & 23 & 33 & 31 & 19 \\
\hline \multirow[b]{2}{*}{11} & $\underline{22}$ & $\underline{32}$ & $\underline{33}$ & $\underline{0}$ & $\underline{55}$ & $\underline{24}$ & $\underline{30}$ & $\underline{25}$ & $\underline{32}$ & $\underline{16}$ \\
\hline & 27 & 30 & 33 & 0 & 50 & 25 & 25 & 30 & 32 & 20 \\
\hline \multirow[b]{2}{*}{12} & $\underline{74}$ & $\underline{44}$ & $\underline{12}$ & $\underline{32}$ & $\underline{25}$ & $\underline{39}$ & $\underline{15}$ & $\underline{35}$ & $\underline{20}$ & $\underline{29}$ \\
\hline & 68 & 30 & 8 & 25 & 27 & 37 & 14 & 31 & 26 & 27 \\
\hline \multirow[b]{2}{*}{13} & $\underline{22}$ & $\underline{22}$ & $\underline{36}$ & $\underline{22}$ & $\underline{20}$ & $\underline{18}$ & $\underline{24}$ & $\underline{8}$ & $\underline{30}$ & $\underline{45}$ \\
\hline & 27 & 27 & 33 & 28 & 18 & 22 & 28 & 6 & 33 & 40 \\
\hline \multirow[b]{2}{*}{14} & $\underline{74}$ & $\underline{22}$ & $\underline{55}$ & $\underline{19}$ & $\underline{30}$ & 24 & $\underline{30}$ & $\underline{33}$ & $\underline{16}$ & $6 \underline{65}$ \\
\hline & 68 & 20 & 45 & 14 & 27 & 22 & 29 & 37 & 21 & 53 \\
\hline \multirow[b]{2}{*}{15} & $\underline{21}$ & $\underline{32}$ & $\underline{63}$ & 17 & $\underline{40}$ & $\underline{78}$ & $\underline{44}$ & $\underline{0}$ & $\underline{21}$ & 15 \\
\hline & 25 & 27 & 53 & 18 & 38 & 72 & 42 & 0 & 23 & 20 \\
\hline \multirow[b]{2}{*}{16} & $\underline{47}$ & $\underline{33}$ & $\underline{45}$ & $\underline{41}$ & $\underline{27}$ & $\underline{25}$ & $\underline{3}$ & $\underline{50}$ & $\underline{56}$ & $\underline{35}$ \\
\hline & 52 & 28 & 45 & 47 & 22 & 22 & 2 & 47 & 51 & 33 \\
\hline
\end{tabular}

\section{TESTING OF THE DEVICE FOR MEASURING VIBRATIONS AND RUNOUT}

Testing of this device was performed on the experimental collector. Tests were carried out at the rotation speed of $3000 \mathrm{rev} / \mathrm{min}$. The results are shown on Fig. 3.

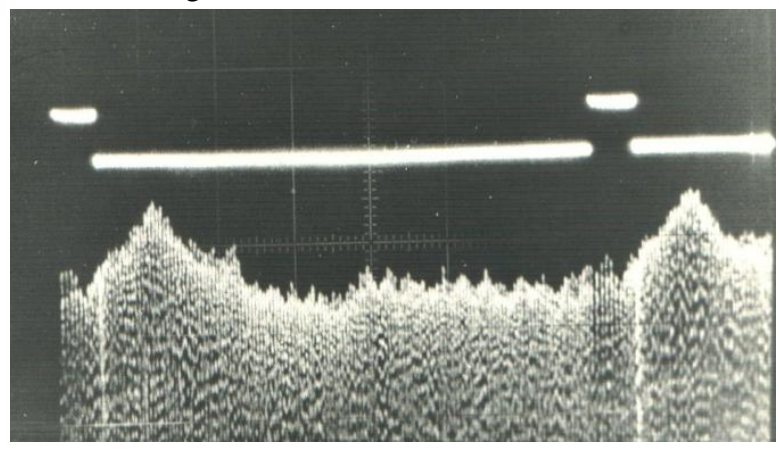

On the oscilloscope screen we can see every collector plate, the runout of collector, protrusion of individual plates.

\section{CONCLUSION}

So the most important parameters of the current collection systems are the intensity of the sparking under brushes, uniformity of current distribution on parallel brushes, vibrations and runout slip rings and the state of their surface.

For monitoring these parameters Ecotech Ltd (Pskov) develops a hardware-software complex. The complex consists the following basic devices:

- device for monitoring the intensity of sparking under brushes,

- device for measuring current of brushes,

- device for measuring vibrations and runout of slip rings or collectors.

These all devices were successfully tested on the experimental stand Ecotech Ltd.

\section{$\mathrm{X}$ ACKNOWLEDGMENTS}

Development, manufacture and testing of hardwaresoftware complex are supported by the Foundation for Assistance to Small Innovative Enterprises in the scientific and technical field (Russia). Contract No $10463 \mathrm{p} / 18672$.

\section{REFERENCES}

[1] Brush-contact device of TVV and TVF types turbo-generators. Operating instruction. - 1988.

[2] Typical instruction for operation and maintenance of slip rings unit of turbo-generators of $63 \mathrm{MW}$ and above. - 2000.

[3] Y. Rodionov, "Design, manufacture and testing of the model of a hardware-software complex of continuous monitoring of the current collection systems of turbo-generators," Ecotech Ltd, Pskov, Russia, Tech. Rep. 01201271200, 2012. 